\title{
LEED 2009 Recertification of Existing Buildings: Bonus Effect
}

\author{
Svetlana Pushkar (D)
}

check for updates

Citation: Pushkar, S. LEED 2009 Recertification of Existing Buildings: Bonus Effect. Sustainability 2021, 13, 10796. https://doi.org/10.3390/ su131910796

Academic Editors: Serdar Durdyev, Amir Mahdiyar, Syuhaida Ismail and Asterios Bakolas

Received: 25 August 2021

Accepted: 26 September 2021

Published: 28 September 2021

Publisher's Note: MDPI stays neutral with regard to jurisdictional claims in published maps and institutional affiliations.

Copyright: (C) 2021 by the author. Licensee MDPI, Basel, Switzerland. This article is an open access article distributed under the terms and conditions of the Creative Commons Attribution (CC BY) license (https:/ / creativecommons.org/licenses/by/ $4.0 /)$.
Department of Civil Engineering, Ariel University, Ariel 40700, Israel; svetlanap@ariel.ac.il

\begin{abstract}
This study aimed to assess the impact of a four-point bonus system on recertification in Leadership in Energy and Environmental Design for Existing Buildings (LEED-EB) 2009 office space projects in four metropolitan cities: Washington, DC, Chicago, New York, and San Francisco. We analyzed 123 paired LEED-EB 2009 projects where each pair (i.e., certification-recertification) was used on the same building. The percentage of average score was used to evaluate differences in certification-recertification strategies: (1) gold-gold with and without the bonus, (2) silver-gold with and without the bonus, and (3) platinum-platinum with the bonus. The replication method was used to evaluate the overall tendency for four metropolitan cities. We found that while LEED-EB 2009 projects used a four-point recertification bonus, achievements in the materials and resources (MR) and indoor environmental quality (EQ) categories declined in each of the four metropolitan cities. We identified this overall tendency at three levels of certification-recertification: gold-gold, silver-gold, and platinum-platinum. We hypothesized that if the use of a four-point recertification bonus in LEED-EB 2009 projects resulted in lower achievements in the MR/EQ categories, then the use of the 10-point recertification bonus in LEED-EB 4.1 projects could lead to a deterioration in the sustainability of existing office buildings.
\end{abstract}

Keywords: LEED-EB 2009; LEED-EB v4.1; office-type projects recertification bonus; sustainability

\section{Introduction}

The building sector has huge environmental impacts, including those related to greenhouse gas (GHG) emissions. Both the production and operational stages of building involve the production of building materials, and energy consumption from heating, cooling, and lighting operations generates $40 \%$ of the GHG emissions produced in this area [1]. To ensure they are building in a sustainable way, building practitioners use commonly accepted green rating systems [2].

Green rating systems measure building sustainability using a list of several commonly accepted environmental categories, such as sustainable site, energy, water, materials, and well-being. Each of the categories has one/several credits based on performance requirements. These systems are classified as point-based [3]. The systems used differ from country to country due to variations in climatic conditions, the availability of natural resources, environmental problems, building technologies used, building market demand, and demographic and cultural patterns [4].

However, some systems, for example, the Building Research Establishment's Environmental Assessment Method (BREEAM), Leadership in Energy and Environmental Design (LEED), and Deutsche Gesellschaft für Nachhaltiges Bauen (DGNB), which were first developed for the United Kingdom, the United States, and Germany, respectively, are currently considered to be internationally used [2]. In addition, Ling developed the Green Audit Award (GAA) system based on the LEED protocol [5]. The GAA system contains a procedure for developing a unique environmental improvement plan for each retrofitted building [5]. However, in this paper, we focus on the LEED certification, which is currently used in 165 countries worldwide [6].

According to the literature, green-certified buildings have been proven to be environmentally efficient. Eisenstein et al. [7] compared LEED-certified existing office buildings 
to a baseline of conventional office buildings in California, USA. It was found that compared with baseline buildings, LEED-certified buildings produced a significantly lower concentration of greenhouse gases: $50 \%$ less due to water consumption, $48 \%$ less due to solid waste management, and 5\% less due to transportation. Phillips et al. [8] compared 12 LEED-certified buildings with 12 non-LEED-certified buildings on the University of Utah campus in the USA and concluded that the indoor air quality of LEED-certified buildings was better than that of non-LEED-certified buildings because the LEED-certified buildings demonstrated particulate matter concentrations that were approximately half those in non-LEED certified buildings. Scofield et al. [9] measured the energy performance of 4417 commercial office buildings in 10 major US cities, including 551 LEED-certified buildings. The authors concluded that LEED-certified offices had site energy savings of $11 \%$. Thus, encouraging green certification is a very important issue.

Encouragement measures may be divided into external and internal. External measures are LEED-related mandatory polices and incentive-based practices that were created as separate standards and regulations outside of the green rating system [10]. Internal measures are bonus points that are embedded in a green rating system as a part of the total credits awarded [11].

With respect to external encouragement measures, many studies have recognized mandatory polices as a main stimulator of driving companies to undergo the LEED certification process [10,12-15]. For example, Fuerst et al. [15] evaluated LEED-certified buildings across 174 metropolitan and micropolitan statistical areas and revealed that only mandatory polices had significant influences on LEED adoption, whereas incentive-based practices were not influential. However, York et al. [16] revealed that in addition to mandatory polices, incentive-based practices such as social market intermediaries, movement organizations, and environmental entrepreneurs also influence LEED adoption. Thus, it has been proven that the external measures such as mandatory policies and incentive-based practices have stimulating effects on LEED adoption.

However, it is doubtful that internal encouragement measures, such as the use of bonus points, a practice that is included in the LEED certification system, would have a similar effect to the previously discussed external encouragement measures. This is due to "the principle of least effort", which has been revealed in LEED certification throughout the years. The principle of least effort was first noted by Fuerst [17], who reviewed 2000 LEED-certified projects in the USA and concluded that the achievement of LEED certification is preferable to improving green building design. This conclusion was based on the revealed clustering of awarded scores near the lower bounds of certified (40 points), silver (50 points), gold (60 points), and platinum ( 80 points) certifications. Subsequently, many other researchers have confirmed this issue.

Wu et al. [18] and Wu et al. [19] studied 5340 and 3416 LEED projects, respectively, worldwide during 2007-2015 and confirmed that, in these projects, the total number of certification points achieved by each project was very close to the lower certification limits in the certified, silver, gold, and platinum certifications. Pushkar and Verbitsky [20] analyzed 920 silver and gold LEED projects certified in the USA in 2016 and noticed that point totals of 50-53 and 60-64 were achieved for silver and gold projects, respectively. Pushkar and Verbitsky [21] studied 2289 silver and gold LEED projects certified in the USA up to November 2017 and reported that silver and gold projects achieved about 51-57 points and 62-71 points, respectively. In contrast, Flowers et al. [22], who reviewed 4486 LEED projects over a longer period from 2000 to 2016, reported that the principle of least effort became less relevant in the later years of the study period.

These studies caught our attention because they show that the principle of least effort can be applied to LEED recertification projects. Moreover, this phenomenon may be more noticeable in recertified buildings than in the aforementioned certification cases. The purported reason for this is that bonus points are offered to buildings already using the LEED certification (LEED-EB 2009 and v4.1) process to encourage recertification. 
LEED-EB 2009 is composed of five main categories-sustainable sites (SS, 26 points), water efficiency (WE, 14 points), energy and atmosphere (EA, 35 points), materials and resources (MR, 10 points), and indoor environmental quality (EQ, 15 points) - and two additional categories - innovation in operations (IO, 6 points) and regional priority (RP, 4 points) - giving a possible total of 110 points [23]. This is the first version of the existing building-relevant LEED system that awards a Certified Design and Construction (SSc1) credit of four bonus points during recertification for projects that have previously been certified under LEED-NC (newly constructed buildings), LEED-C\&S (core and shell buildings), LEED-CI (commercial interiors), or LEED for Schools [23]. The recertification bonus credits aim to stimulate environmentally sensitive projects to work towards higher achievements. LEED-EB 2009 encourages recertification to be performed yearly, while making it mandatory every 5 years [23]. In this way, recertification has become a very important issue related to ongoing green performance throughout a building's life cycle [24].

The current version, LEED-EB v4.1, directly introduces five ongoing types of performance: transportation (14 points), water (15 points), energy (33 points), waste (8 points), and indoor environmental quality (20 points). This gives a total of 90 points. There are also some additional categories in which credits can be achieved, such as rainwater management (SS category), enhanced refrigerant management (EA category), and innovation (IO category), giving a total of 10 points [24]. In addition, this system encourages recertification by awarding 10 bonus points for buildings undergoing recertification. Therefore, the total number of LEED-EB v4 points that can be achieved is 110.

If the four bonus points applied in LEED-EB 2009 is not enough to move a building from certified ( 40 points) to silver (50 points) or from silver (50 points) to gold (60 points) and additional credits should be involved, the 10 bonus points used in LEED-EB v4.1 can be applied. However, in this recertification process, all initial certification points awarded must remain at the same level. Thus, in theory, there are two different paths for achieving the next certification level: LEED-EB 2009 and LEED-EB v4.1. When using the LEED-EB 2009 recertification process, previously earned certification points must be retained during the recertification process, and additional effort and money need to be invested to earn a few extra points. When using recertification for LEED-EB v4.1 projects, it is enough to keep previously received points and use a bonus of 10 points to automatically transfer the project to the next level. Maintaining certification results across all categories at recertification is an important issue as it should help to increase the LEED-EB certification level.

However, according to previously published empirical results, the five main LEED categories have different priorities. In particular, SS, WE, and EA are high-achievement categories, and EQ and MR are low-achievement categories [19,20]. It can be assumed that the bonus points associated with recertification may fit this pattern, that is, a decrease in performance in the MR and EQ categories. Trovato et al. [25] noted that "the use of sustainable materials reduces the building's carbon footprint index by $54.1 \%$ after retrofit compared to standard materials". However, no empirical studies of LEED-EB recertification results can been found in the related literature.

The aim of this study is to assess the impact of the bonus points approach on strategies to transition LEED-EB 2009 projects from certification to recertification. The main question is whether the principle of least effort, which was previously shown to be relevant to LEED certified projects $[17,19,20]$, is also relevant to the recertification of LEED-EB projects with the bonus system. To answer this question, we examined silver, gold, and platinum LEEDEB 2009 office space projects that were both certified and recertified in four metropolitan cities in the USA: Washington, DC, Chicago, New York, and San Francisco. In the present study, the analysis was restricted to LEED-EB 2009 recertified buildings, as there are not enough projects available that have undergone recertification through the newer LEED-EB v4.1 system.

This study addresses an issue of great social importance-application of the bonus aspect in the LEED-EB 2009 system. In addition, the suggested study design could help us to evaluate the effectiveness of the bonus system used in LEED-EB v4.1 recertification projects. 


\section{Materials and Methods}

\subsection{Data Collection and Replication Method}

To increase the homogeneity of the group and decrease the influence of uncontrolled factors on the assessment of LEED-EB 2009 certification-recertification strategies, we aimed to select at least four metropolitan cities with LEED-EB 2009 office space projects certified at the silver, gold, and platinum levels. According to the US Green Building Council (USGBC) [26] and Green Building Information Gateway (GBIG) [27] databases, Washington DC, Chicago, New York, and San Francisco are the four metropolitan cities with the most LEED-EB 2009 certification-recertification pairs within an office building project.

The four metropolitan cities were analyzed separately, which allowed us to use the replication method. Meehl [28] (p. 111) vividly described the benefits of using the replication method: "Any working scientist is more impressed with 2 replications in each of 6 highly dissimilar experimental contexts than he is with 12 replications of the same experiment." Therefore, reproduction of the same effect in four metropolitan cities may mean that the effect shown is real and is not achieved through pseudoreplication [29].

Table 1 shows the number of LEED-EB 2009 office space certification-recertification projects carried out within a building found in the USGBC database in the four metropolitan cities. In line with the distribution of LEED-EB 2009 projects among the four metropolitan cities, we focused on the following certification-recertification projects: platinum-platinum with bonus, gold-gold with bonus, gold-gold without bonus, silver-gold with bonus, and silver-gold without bonus.

Table 1. Distribution of LEED-EB 2009 office space certification-recertification projects with and without a bonus at different levels of certification in four metropolitan cities.

\begin{tabular}{|c|c|c|c|c|}
\hline \multirow{2}{*}{$\begin{array}{l}\text { LEED-EB } 2009 \text { Office Space Project } \\
\text { (Certification-Recertification on the } \\
\text { Same Building) }\end{array}$} & \multicolumn{4}{|c|}{ Number of Paired Projects Identified } \\
\hline & Washington, DC & Chicago & New York & San Francisco \\
\hline Platinum-platinum with bonus ${ }^{1}$ & 8 & 1 & 0 & 5 \\
\hline Platinum-platinum without bonus & 1 & 0 & 0 & 1 \\
\hline Gold-gold with bonus ${ }^{1}$ & 13 & 6 & 8 & 10 \\
\hline Gold-gold without bonus ${ }^{1}$ & 8 & 4 & 5 & 2 \\
\hline Silver-silver with bonus & 1 & 1 & 1 & 0 \\
\hline Silver-silver without bonus & 1 & 0 & 0 & 0 \\
\hline Certified-certified with bonus & 0 & 0 & 1 & 0 \\
\hline Certified-certified without bonus & 0 & 0 & 0 & 0 \\
\hline Gold-platinum with bonus & 7 & 4 & 0 & 1 \\
\hline Gold-platinum without bonus & 0 & 0 & 0 & 2 \\
\hline Silver-gold with bonus ${ }^{1}$ & 4 & 4 & 7 & 1 \\
\hline Silver-gold without bonus ${ }^{1}$ & 2 & 4 & 4 & 0 \\
\hline Certified-silver with bonus & 0 & 0 & 1 & 0 \\
\hline Certified-silver without bonus & 0 & 0 & 0 & 0 \\
\hline Certified-gold with bonus & 0 & 0 & 1 & 0 \\
\hline Certified-gold without bonus & 0 & 0 & 0 & 0 \\
\hline Certified-platinum with bonus & 1 & 0 & 0 & 0 \\
\hline Silver-gold-platinum without bonus & 0 & 1 & 0 & 0 \\
\hline Gold-certified with bonus & 0 & 0 & 0 & 2 \\
\hline
\end{tabular}

\footnotetext{
${ }^{1}$ The analyzed certification-recertification projects.
}

\subsection{Statistical Analysis}

It is well known that LEED data are associated with an ordinal scale; consequently, the normal distribution assumption was not applicable [30]. In this context, the exact Wilcoxon's signed rank nonparametric test was the appropriate significance test to use. However, Wilcoxon's signed rank test could be used if the number of primary sample units (that is, paired LEED certification-recertification projects on the same buildings) was greater than or equal to 8 [31]. Table 1 demonstrates that 15 of the 20 groups contained less than 8 primary sampling units. Therefore, we only used descriptive statistics, namely, the 
percentage of average score (PAS; the ratio of achieved points to maximal points, expressed as a percentage) to assess the performance of the LEED data [32].

\section{Results}

\subsection{Gold Certification-Recertification with Bonus and without Bonus}

Figure 1 shows the PASs of LEED-EB 2009 categories for gold certified-recertified projects in four cities: Washington DC, Chicago, New York, and San Francisco. As shown in the left panel (certification-recertification with bonus), in each of the four cities, the PASs increased in the SS category for recertification compared with certification (marked with a dotted line), whereas the PASs in the MR and EQ categories decreased at recertification projects compared with certification (marked with a solid line).
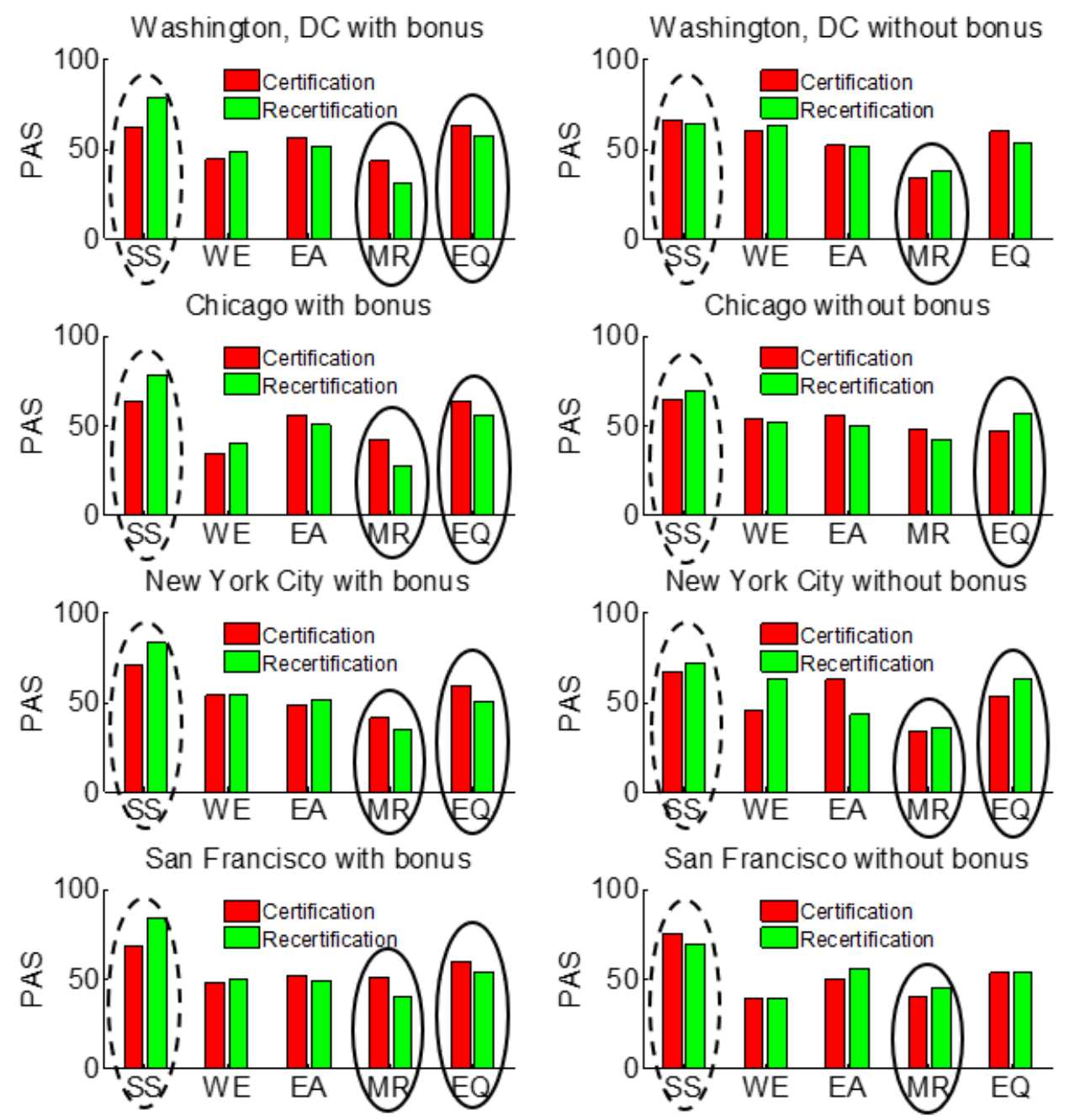

Figure 1. Gold certification-recertification projects with and without a bonus: LEED-EB 2009 credits. The bonus-included SS category is marked with a dotted line, and the MR and EQ categories are marked with a solid line.

As shown in the right panel (certification-recertification without a bonus), there was no clear tendency for the change in the PASs in the SS category in the certificationrecertification results (marked with a dotted line), whereas the PASs in the MR/EQ categories increased at recertification compared with certification (marked with a solid line). There were two exceptions: the EQ category in Washington DC and the MR category in Chicago, for which the results at recertification were lower than those at certification. This was true for certification-recertification cases with a bonus and without a bonus. Thus, in a further step, the MR and EQ categories were analyzed on a credit level. 
Regarding the WE and EA categories, there was no clear tendency for a change in PASs between certification-recertification cases with a bonus and those without a bonus. Therefore, analyses of the WE and EA categories at the credit level are omitted from this paper.

Table 2 shows the PASs related to the MR credits in the four studied cities. When comparing the PASs in the MR category achieved at certification, two groups of credits were recognized: credits related to decreased PASs in the MR category for recertification cases with a bonus (bold italic font) and credits associated with the increased PASs in the MR category for recertification cases without a bonus (bold font). The credits that belong to these two groups are mostly from the Sustainable Purchasing issue, such as MRc1 Sustainable Purchasing-Ongoing Consumables, MRc2.1 Sustainable Purchasing-ElectricPowered Equipment, MRc2.2 Sustainable Purchasing-Furniture, and MRc3 Sustainable Purchasing-Facility Alterations and Additions. Chicago was found to be an exception to this tendency, because only MRc9 Solid Waste Management-Facility Alterations and Additions was found to be associated with decreased PASs in certification-recertification cases with a bonus and increased PASs in certification-recertification cases without a bonus. Thus, in Chicago, at the category level, the PASs in the MR category at recertification were lower than those achieved at certification for cases with and without a bonus (Figure 1).

Table 2. Gold certification-recertification with bonus (bold italic font) and without bonus (bold font): PASs of the MR credits.

\begin{tabular}{|c|c|c|c|c|c|c|c|c|c|}
\hline \multirow{2}{*}{ Credit ${ }^{1}$} & \multirow[t]{2}{*}{ Points } & \multicolumn{2}{|c|}{ with Bonus } & \multicolumn{2}{|c|}{ without Bonus } & \multicolumn{2}{|c|}{ with Bonus } & \multicolumn{2}{|c|}{ without Bonus } \\
\hline & & Cert & Recert & Cert & Recert & Cert & Recert & Cert & Recert \\
\hline & & \multicolumn{4}{|c|}{ Washington, DC } & \multicolumn{4}{|c|}{ Chicago } \\
\hline MRc1 & 1 & 8 & 0 & 0 & 0 & 0 & 0 & 0 & 25 \\
\hline MRc2.1 & 1 & 31 & 15 & 0 & 22 & 0 & 17 & 25 & 25 \\
\hline MRc2.2 & 1 & 15 & 0 & 0 & 22 & 17 & 0 & 25 & 0 \\
\hline MRc3 & 1 & 31 & 0 & 11 & 11 & 33 & 0 & 25 & 25 \\
\hline MRc4 & 1 & 77 & 92 & 78 & 89 & 83 & 67 & 100 & 75 \\
\hline MRc5 & 1 & 0 & 0 & 0 & 0 & 0 & 0 & 0 & 0 \\
\hline MRc6 & 1 & 92 & 77 & 100 & 56 & 67 & 50 & 100 & 100 \\
\hline MRc7 & 1 & 46 & 23 & 11 & 44 & 67 & 17 & 50 & 0 \\
\hline MRc8 & 1 & 85 & 85 & 89 & 100 & 100 & 100 & 100 & 100 \\
\hline \multirow[t]{2}{*}{ MRc9 } & 1 & 46 & 15 & 44 & 33 & 50 & 17 & 50 & 75 \\
\hline & & \multicolumn{4}{|c|}{ New York City } & \multicolumn{4}{|c|}{ San Francisco } \\
\hline MRc1 & 1 & 0 & 0 & 0 & 0 & 0 & 0 & 50 & 50 \\
\hline MRc2.1 & 1 & 13 & 0 & 0 & 20 & 10 & 0 & 0 & 50 \\
\hline MRc2.2 & 1 & 13 & 0 & 0 & 0 & 20 & 0 & 0 & 50 \\
\hline MRc3 & 1 & 13 & 13 & 20 & 0 & 30 & 0 & 0 & 0 \\
\hline MRc4 & 1 & 88 & 63 & 0 & 60 & 80 & 80 & 100 & 50 \\
\hline MRc5 & 1 & 0 & 0 & 0 & 0 & 0 & 0 & 0 & 0 \\
\hline MRc6 & 1 & 88 & 75 & 100 & 40 & 100 & 80 & 100 & 100 \\
\hline MRc7 & 1 & 88 & 88 & 100 & 100 & 90 & 100 & 50 & 100 \\
\hline MRc8 & 1 & 88 & 88 & 80 & 100 & 100 & 90 & 100 & 50 \\
\hline MRc9 & 1 & 25 & 25 & 40 & 40 & 80 & 50 & 0 & 0 \\
\hline
\end{tabular}

${ }^{1}$ MRc1 Sustainable Purchasing-Ongoing Consumables; MRc2.1 Sustainable Purchasing-Electric-Powered Equipment; MRc2.2 Sustainable Purchasing_Furniture; MRc3 Sustainable Purchasing_Facility Alterations and Additions; MRc4 Sustainable Purchasing-Reduced Mercury in Lamps; MRc5 Sustainable Purchasing-Food; MRc6 Solid Waste Management—Waste Stream Audit; MRc7 Solid Waste Management-Ongoing Consumables; MRc8 Solid Waste Management_Durable Goods; MRc9 Solid Waste Management-Facility Alterations and Additions.

Table 3 demonstrates that, in Chicago and New York City, one-third of EQ credits had decreased PASs at recertification when a bonus was included (bold italic font) and increased PASs at recertification when a bonus was not included (bold font). In Washington DC, most of the EQ credits had decreased PASs at recertification compared with at certification for cases both with and without a bonus. The only exceptions were the credits EQc1.1 Indoor 
Air Quality Best Management Practices (IAQ BMP)—Indoor Air Quality Management Program and EQc1.5 IAQ BMP-IAQ Management for Facility Alterations and Additions, for which the PASs were higher at recertification than at certification for a case that did not involve a bonus. This is why, in Washington DC, at the category level, the PASs in the EQ category at recertification were lower than at certification for recertification cases both with and without a bonus (Figure 1).

Table 3. Gold certification-recertification with bonus (bold italic font) and without bonus (bold font): PASs of the EQ credits.

\begin{tabular}{|c|c|c|c|c|c|c|c|c|c|}
\hline \multirow{2}{*}{ Credit $^{1}$} & \multirow[t]{2}{*}{ Points } & \multicolumn{2}{|c|}{ with Bonus } & \multicolumn{2}{|c|}{ without Bonus } & \multicolumn{2}{|c|}{ with Bonus } & \multicolumn{2}{|c|}{ without Bonus } \\
\hline & & Cert & Recert & Cert & Recert & Cert & Recert & Cert & Recert \\
\hline & & \multicolumn{4}{|c|}{ Washington, DC } & \multicolumn{4}{|c|}{ Chicago } \\
\hline EQc1.1 & 1 & 92 & 77 & 89 & 100 & 100 & 53 & 75 & 100 \\
\hline EQc1.2 & 1 & 0 & 0 & 0 & 0 & 0 & 0 & 0 & 0 \\
\hline EQc1.3 & 1 & 8 & 0 & 22 & 0 & 0 & 0 & 0 & 0 \\
\hline EQC1.4 & 1 & 92 & 92 & 89 & 89 & 83 & 63 & 75 & 100 \\
\hline EQc1.5 & 1 & 54 & 38 & 11 & 22 & 17 & 17 & 0 & 0 \\
\hline EQc2.1 & 1 & 54 & 62 & 67 & 56 & 100 & 33 & 75 & 50 \\
\hline EQc2.2 & 1 & 92 & 92 & 67 & 44 & 83 & 67 & 50 & 75 \\
\hline EQc2.3 & 1 & 0 & 0 & 0 & 0 & 0 & 0 & 0 & 0 \\
\hline EQc2.4 & 1 & 8 & 0 & 11 & 11 & 50 & 33 & 0 & 25 \\
\hline EQc3.1 & 1 & 100 & 100 & 100 & 100 & 100 & 100 & 100 & 100 \\
\hline EQc3.2 & 1 & 100 & 92 & 89 & 89 & 100 & 100 & 50 & 100 \\
\hline EQc3.3 & 1 & 100 & 92 & 100 & 100 & 100 & 100 & 100 & 75 \\
\hline EQc3.4 & 1 & 100 & 92 & 100 & 100 & 100 & 67 & 100 & 75 \\
\hline EQc3.5 & 1 & 62 & 69 & 67 & 22 & 50 & 67 & 0 & 50 \\
\hline \multirow[t]{2}{*}{ EQc3.6 } & 1 & 85 & 54 & 89 & 67 & 67 & 83 & 75 & 100 \\
\hline & & \multicolumn{4}{|c|}{ New York City } & \multicolumn{4}{|c|}{ San Francisco } \\
\hline EQc1.1 & 1 & 100 & 100 & 100 & 100 & 50 & 20 & 80 & 100 \\
\hline EQc1.2 & 1 & 0 & 0 & 0 & 0 & 10 & 10 & 100 & 100 \\
\hline EQc1.3 & 1 & 38 & 0 & 0 & 0 & 20 & 10 & 50 & 0 \\
\hline EQC1.4 & 1 & 88 & 68 & 60 & 80 & 80 & 80 & 100 & 100 \\
\hline EQC1.5 & 1 & 25 & 0 & 20 & 40 & 20 & 20 & 0 & 0 \\
\hline EQc2.1 & 1 & 25 & 15 & 60 & 80 & 40 & 10 & 80 & 100 \\
\hline EQc2.2 & 1 & 63 & 38 & 20 & 40 & 100 & 100 & 50 & 50 \\
\hline EQc2.3 & 1 & 0 & 0 & 0 & 0 & 10 & 0 & 0 & 0 \\
\hline EQc2.4 & 1 & 13 & 11 & 40 & 60 & 20 & 20 & 0 & 0 \\
\hline EQc3.1 & 1 & 100 & 100 & 80 & 100 & 100 & 100 & 100 & 100 \\
\hline EQc3.2 & 1 & 88 & 75 & 100 & 100 & 100 & 90 & 50 & 50 \\
\hline EQc3.3 & 1 & 100 & 100 & 80 & 100 & 100 & 90 & 100 & 100 \\
\hline EQc3.4 & 1 & 88 & 68 & 60 & 80 & 100 & 80 & 100 & 50 \\
\hline EQc3.5 & 1 & 88 & 88 & 80 & 80 & 60 & 70 & 0 & 50 \\
\hline EQc3.6 & 1 & 75 & 50 & 100 & 80 & 90 & 60 & 60 & 100 \\
\hline
\end{tabular}

${ }^{1}$ EQc1.1 Indoor Air Quality Best Management Practices (IAQ BMP)—Indoor Air Quality Management Program; EQc1.2 IAQ BMP—Outdoor Air Delivery Monitoring; EQc1.3 IAQ BMP-Increased Ventilation; EQc1.4 IAQ BMP-Reduce Particulates in Air Distribution; EQc1.5 IAQ BMP_IAQ Management for Facility Alterations and Additions; EQc2.1 Occupant Comfort-Occupant Survey; EQc2.2 Controllability of Systems-Lighting; EQc2.3 Occupant Comfort-Thermal Comfort Monitoring; EQc2.4 Daylight and Views; EQc3.1 Green Cleaning (GC) High Performance Cleaning Program; EQc3.2 GC-Custodial Effectiveness Assessment; EQc3.3 GC-Purchase of Sustainable Cleaning Products and Materials; EQc3.4 GC—Sustainable Cleaning Equipment; EQc3.5 GC—Indoor Chemical and Pollutant Source Control; EQc3.6 GC_-Indoor Integrated Pest Management.

Similar results were observed for San Francisco, where most of the EQ credits had decreased PASs at recertification compared with at certification in cases both with and without a bonus. In this city, EQc1.1 Indoor Air Quality Best Management PracticesIndoor Air Quality Management Program and EQc2.1 Occupant Comfort-Occupant Survey were the only exceptions, showing decreased PASs at recertification in a case involving a bonus and increased PASs at recertification in a case not involving a bonus. Therefore, at the category level, the PASs in the EQ category were lower at recertification 
compared with at certification for recertification cases involving a bonus, and PASs were almost the same for recertification cases not involving a bonus (Figure 1).

\subsection{Silver Certification-Gold Recertification with Bonus and without a Bonus}

Figure 2 shows that in silver certification-gold recertification cases, only the MR category demonstrated the tendency previously revealed for gold certification-recertification cases (Figure 1). In particular, compared with the certification results, the recertification with bonus approach (left panel) showed increased PASs in the SS category (marked with a dotted line) and decreased PASs in the MR category (marked with a solid line). Compared with the certification results, the recertification without a bonus approach (left panel) showed no clear tendency related to changing the PASs of SS-related certificationrecertification results (marked with a dotted line), whereas the PASs in the MR category (marked with a solid line) increased. This was revealed for Washington DC, Chicago, and New York City. In Washington DC, the same tendency was noticed for PASs in the EQ category. In San Francisco, data were only available for recertification with bonus cases (left panel). In this city, it was also found that compared with the certification results, the PASs in the SS category (marked with a dotted line) increased at recertification and the PASs in the MR category (marked with a solid line) decreased. Considering the WE and EA results at the silver certification-gold recertification level, there was no clear tendency for an increase in PASs for cases both with and without a bonus. As a result, the MR category was only analyzed at the credit level.

Table 4 shows the credits that were responsible for this tendency for different MRrelated PASs during recertification with a bonus (decreased PASs, bold italic font) and without a bonus (increased PASs, bold font). In Washington DC and Chicago, MRc2.1 Sustainable Purchasing-Electric-Powered Equipment and two credits from Waste Management, MRc7 Solid Waste Management-Ongoing Consumables and MRc8 Solid Waste Management-Durable Goods, were the most influential. In New York City, the most influential credits were two Sustainable Purchasing credits, MRc2.1 Sustainable PurchasingElectric-Powered Equipment and MRc4 Sustainable Purchasing-Reduced Mercury in Lamps, as well as MRc9 Solid Waste Management-Facility Alterations and Additions.

\subsection{Platinum Certification-Recertification with Bonus}

Figure 3 shows the PASs achieved for the five categories in two cites-Washington DC and San Francisco-for a platinum certification-recertification cases involving a bonus; no data were available for case of platinum certification-recertification not involving a bonus. In addition, no data were available for platinum certification-recertification cases in Chicago and New York City either with or without a bonus. According to the results revealed for Washington DC and San Francisco, the PASs in the SS category were greater at certification compared with at recertification (marked with a dotted line), whereas the PASs in the MR and EQ categories were lower (marked with a solid line). Considering the WE and EA categories, there was no clear tendency for a change in the certificationrecertification PAS results. Therefore, in the next step, only the MR and EQ categories were analyzed at the credit level. 

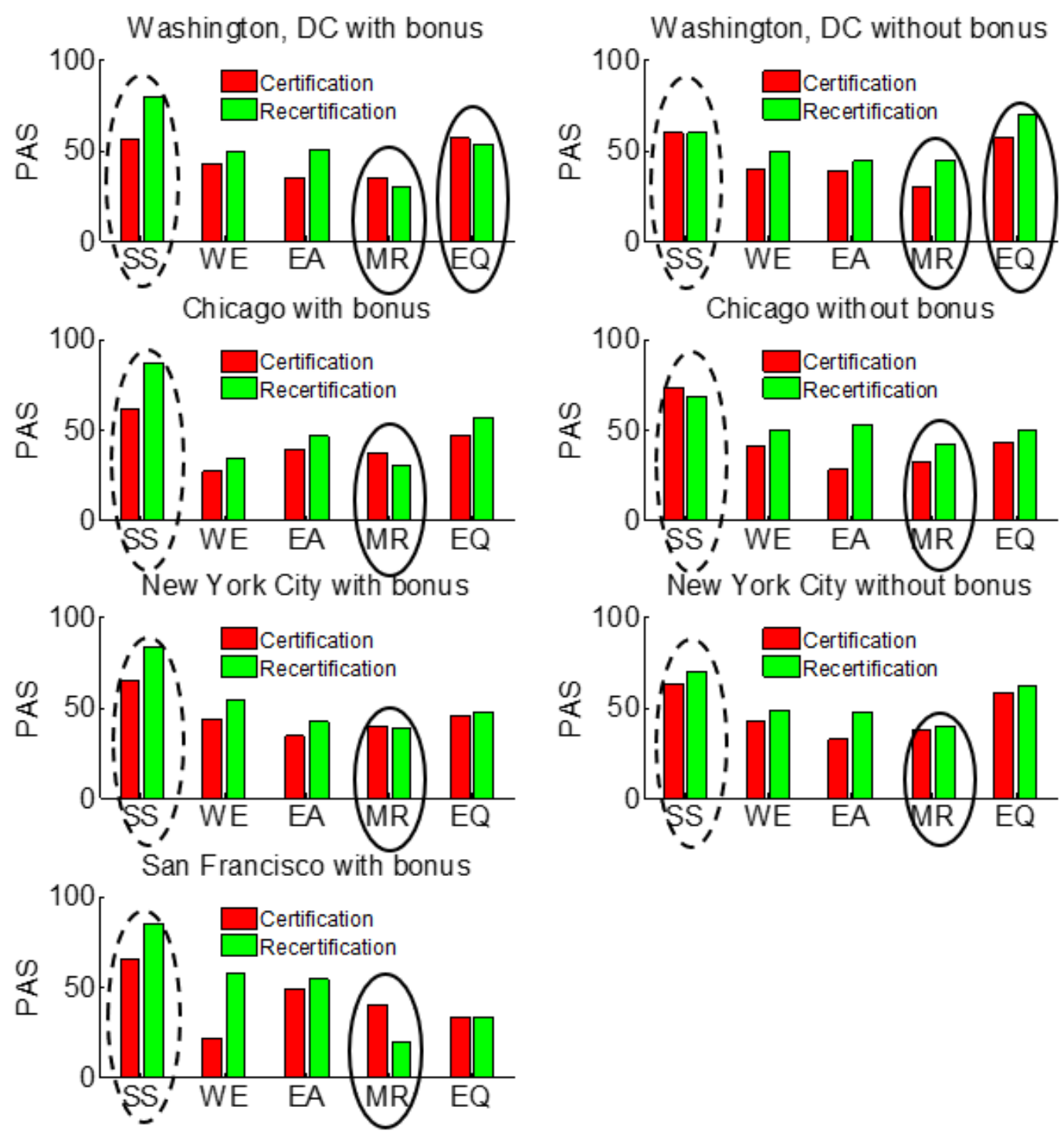

Figure 2. Silver certification-gold recertification cases with and without a bonus: LEED-EB 2009 credits. The bonus-included SS category is marked with a dotted line, and the MR and EQ categories are marked with solid lines.
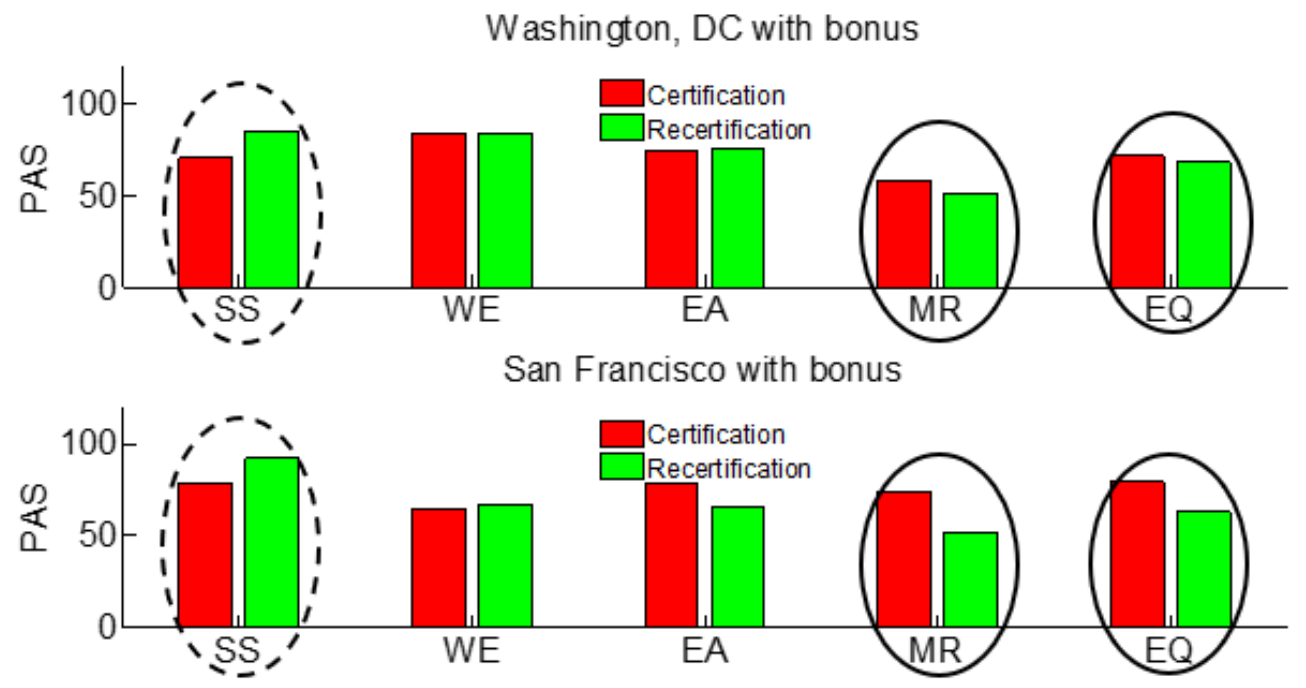

Figure 3. Platinum certification-recertification cases involving a bonus. The bonus-included SS category is marked with a dotted line, and the MR and EQ categories are marked with solid lines. 
Table 4. Silver certification-gold recertification cases with (bold italic font) and without a bonus (bold font): PASs of the MR credits.

\begin{tabular}{|c|c|c|c|c|c|c|c|c|c|}
\hline \multirow{2}{*}{ Credit ${ }^{1}$} & \multirow[t]{2}{*}{ Points } & \multicolumn{2}{|c|}{ with Bonus } & \multicolumn{2}{|c|}{ without Bonus } & \multicolumn{2}{|c|}{ with Bonus } & \multicolumn{2}{|c|}{ without Bonus } \\
\hline & & Cert & Recert & Cert & Recert & Cert & Recert & Cert & Recert \\
\hline & & \multicolumn{4}{|c|}{ Washington, DC } & \multicolumn{4}{|c|}{ Chicago } \\
\hline MRc1 & 1 & 0 & 0 & 0 & 0 & 0 & 0 & 0 & 0 \\
\hline MRc2.1 & 1 & 0 & 0 & 0 & 50 & 25 & 0 & 0 & 25 \\
\hline MRc2.2 & 1 & 0 & 0 & 0 & 0 & 25 & 25 & 0 & 25 \\
\hline MRc3 & 1 & 0 & 0 & 0 & 0 & 25 & 0 & 0 & 0 \\
\hline MRc4 & 1 & 100 & 100 & 100 & 100 & 75 & 50 & 0 & 75 \\
\hline MRc5 & 1 & 0 & 0 & 0 & 0 & 0 & 0 & 0 & 0 \\
\hline MRc6 & 1 & 100 & 75 & 50 & 100 & 50 & 25 & 100 & 100 \\
\hline MRc7 & 1 & 75 & 25 & 50 & 70 & 50 & 25 & 25 & 75 \\
\hline MRc8 & 1 & 75 & 100 & 100 & 100 & 75 & 100 & 50 & 75 \\
\hline \multirow[t]{2}{*}{ MRc9 } & 1 & 0 & 0 & 0 & 50 & 75 & 50 & 75 & 100 \\
\hline & & \multicolumn{4}{|c|}{ New York City } & \multicolumn{4}{|c|}{ San Francisco } \\
\hline MRc1 & 1 & 0 & 0 & 0 & 0 & 0 & 0 & - & - \\
\hline MRc2.1 & 1 & 14 & 14 & 0 & 25 & 0 & 0 & - & - \\
\hline MRc2.2 & 1 & 0 & 14 & 25 & 25 & 0 & 0 & - & - \\
\hline MRc3 & 1 & 29 & 0 & 25 & 25 & 0 & 0.00 & - & - \\
\hline MRc4 & 1 & 71 & 57 & 25 & 75 & 0 & 100 & - & - \\
\hline MRc5 & 1 & 0 & 0 & 0 & 0 & 0 & 0 & - & - \\
\hline MRc6 & 1 & 100 & 100 & 75 & 100 & 100 & 0 & - & - \\
\hline MRc7 & 1 & 100 & 100 & 75 & 75 & 100 & 100 & - & - \\
\hline MRc8 & 1 & 71 & 86 & 75 & 75 & 100 & 0 & - & - \\
\hline MRc9 & 1 & 14 & 14 & 25 & 50 & 0 & 0 & - & - \\
\hline
\end{tabular}

${ }^{1}$ MRc1 Sustainable Purchasing-Ongoing Consumables; MRc2.1 Sustainable Purchasing-Electric-Powered Equipment; MRc2.2 Sustainable Purchasing-Furniture; MRc3 Sustainable Purchasing-Facility Alterations and Additions; MRc4 Sustainable Purchasing-Reduced Mercury in Lamps; MRc5 Sustainable Purchasing-Food MRc6 Solid Waste Management-Waste Stream Audit; MRc7 Solid Waste Management-Ongoing Consumables; MRc8 Solid Waste Management-Durable Goods; MRc9 Solid Waste Management-Facility Alterations and Additions.

Table 5 demonstrates that in both Washington DC and San Francisco, Sustainable Purchasing credits, such as MRc2.1 Sustainable Purchasing-Electric-Powered Equipment, MRc2.2 Sustainable Purchasing-Furniture, MRc3 Sustainable Purchasing-Facility Alterations and Additions (bold italic font), were mainly responsible for the decreased PASs in the MR category (Figure 3). In addition, in Washington DC, and San Francisco, the PASs for MRc7 Solid Waste Management-Ongoing Consumables and MRc9 Solid Waste Management-Facility Alterations and Additions decreased at recertification compared with at certification.

Table 6 shows that compared with Washington DC, San Francisco had lower PASs for Indoor Air Quality Best Management Practices and Occupant Comfort issues at recertification compared with at certification. In addition, for Green Cleaning (GC) credits one (EQc3.5 GC-Indoor Chemical and Pollutant Source Control) and two (EQc3.5 GCIndoor Chemical and Pollutant Source Control and EQc3.6 GC-Indoor Integrated Pest Management) credits (bold italic font) had lower PASs at recertification compared with at certification in Washington DC, and San Francisco, respectively. 
Table 5. Platinum certification-recertification cases involving a bonus (bold italic font): PASs of MR credits.

\begin{tabular}{|c|c|c|c|c|c|c|c|c|c|}
\hline \multirow{2}{*}{ Credit ${ }^{1}$} & \multirow[t]{2}{*}{ Points } & \multicolumn{2}{|c|}{ with Bonus } & \multicolumn{2}{|c|}{ without Bonus } & \multicolumn{2}{|c|}{ with Bonus } & \multicolumn{2}{|c|}{ without Bonus } \\
\hline & & Cert & Recert & Cert & Recert & Cert & Recert & Cert & Recert \\
\hline & & \multicolumn{4}{|c|}{ Washington, DC } & \multicolumn{4}{|c|}{ San Francisco } \\
\hline MRc1 & 1 & 0 & 0 & - & - & 20 & 0 & - & - \\
\hline MRc2.1 & 1 & 63 & 38 & - & - & 40 & 20 & - & - \\
\hline MRc2.2 & 1 & 63 & 38 & - & - & 80 & 20 & - & - \\
\hline MRc3 & 1 & 38 & 25 & - & - & 80 & 0 & - & - \\
\hline MRc4 & 1 & 75 & 88 & - & - & 100 & 100 & - & - \\
\hline MRc5 & 1 & 0 & 0 & - & - & 20 & 0 & - & - \\
\hline MRc6 & 1 & 100 & 100 & - & - & 100 & 100 & - & - \\
\hline MRc7 & 1 & 88 & 63 & - & - & 100 & 100 & - & - \\
\hline MRc8 & 1 & 100 & 100 & - & - & 100 & 100 & - & - \\
\hline MRc9 & 1 & 63 & 63 & - & - & 100 & 80 & - & - \\
\hline
\end{tabular}

${ }^{1}$ MRc1 Sustainable Purchasing-Ongoing Consumables; MRc2.1 Sustainable Purchasing-Electric-Powered Equipment; MRc2.2 Sustainable Purchasing-Furniture; MRc3 Sustainable Purchasing-Facility Alterations and Additions; MRc4 Sustainable Purchasing-Reduced Mercury in Lamps; MRc5 Sustainable Purchasing—Food; MRc6 Solid Waste Management-Waste Stream Audit; MRc7 Solid Waste Management-Ongoing Consumables; MRc8 Solid Waste Management-Durable Goods; MRc9 Solid Waste Management-Facility Alterations and Additions.

Table 6. Platinum certification-recertification cases involving a bonus (bold italic font): PASs of EQ credits.

\begin{tabular}{|c|c|c|c|c|c|c|c|c|c|}
\hline \multirow{2}{*}{ Credit ${ }^{1}$} & \multirow[t]{2}{*}{ Points } & \multicolumn{2}{|c|}{ with Bonus } & \multicolumn{2}{|c|}{ without Bonus } & \multicolumn{2}{|c|}{ with Bonus } & \multicolumn{2}{|c|}{ without Bonus } \\
\hline & & Cert & Recert & Cert & Recert & Cert & Recert & Cert & Recert \\
\hline & & \multicolumn{4}{|c|}{ Washington, DC } & \multicolumn{4}{|c|}{ San Francisco } \\
\hline EQc1.1 & 1 & 88 & 100 & - & - & 80 & 0 & - & - \\
\hline EQc1.2 & 1 & 25 & 0 & - & - & 0 & 0 & - & - \\
\hline EQc1.3 & 1 & 38 & 13 & - & - & 80 & 40 & - & - \\
\hline EQc1.4 & 1 & 100 & 100 & - & - & 100 & 100 & - & - \\
\hline EQc1.5 & 1 & 13 & 13 & - & - & 80 & 0 & - & - \\
\hline EQc2.1 & 1 & 75 & 50 & - & - & 100 & 60 & - & - \\
\hline EQc2.2 & 1 & 100 & 100 & - & - & 60 & 60 & - & - \\
\hline EQc2.3 & 1 & 0 & 0 & - & - & 20 & 0 & - & - \\
\hline EQc2.4 & 1 & 63 & 63 & - & - & 80 & 80 & - & - \\
\hline EQc3.1 & 1 & 88 & 100 & - & - & 100 & 100 & - & - \\
\hline EQC3.2 & 1 & 88 & 100 & - & - & 100 & 100 & - & - \\
\hline EQc3.3 & 1 & 100 & 100 & - & - & 100 & 100 & - & - \\
\hline EQc3.4 & 1 & 100 & 100 & - & - & 80 & 80 & - & - \\
\hline EQc3.5 & 1 & 100 & 100 & - & - & 100 & 80 & - & - \\
\hline EQc3.6 & 1 & 100 & 88 & - & - & 100 & 80 & - & - \\
\hline
\end{tabular}

${ }^{1}$ EQc1.1 Indoor Air Quality Best Management Practices (IAQ BMP)—Indoor Air Quality Management Program; EQc1.2 IAQ BMP—Outdoor Air Delivery Monitoring; EQc1.3 IAQ BMP—Increased Ventilation; EQc1.4 IAQ BMP_-Reduce Particulates in Air Distribution; EQc1.5 IAQ BMP_IAQ Management for Facility Alterations and Additions; EQc2.1 Occupant Comfort-Occupant Survey; EQc2.2 Controllability of Systems-Lighting; EQc2.3 Occupant Comfort-Thermal Comfort Monitoring; EQc2.4 Daylight and Views; EQc3.1 Green Cleaning (GC) High Performance Cleaning Program; EQc3.2 GC-Custodial Effectiveness Assessment; EQc3.3 GC-Purchase of Sustainable Cleaning Products and Materials; EQc3.4 GC-Sustainable Cleaning Equipment; EQc3.5 GC-Indoor Chemical and Pollutant Source Control; EQc3.6 GC-Indoor Integrated Pest Management.

\section{Discussion}

In three cases-gold certification-recertification projects, silver certification-gold recertification projects, and platinum certification-recertification projects with a bonusPASs in the MR/EQ categories decreased at recertification. However, for gold certificationrecertification projects and silver certification-gold recertification projects without a bonus, the PASs in the MR/EQ categories increased at recertification. 
It could be suggested that the controversial results for the MR and EQ categories at recertification in cases both with and without a bonus may have been triggered by the ability to gain four bonus points in the SS category. Additionally, low and medium levels of achievement have been shown for the MR and EQ categories in previous empirical studies of LEED-certified projects by other researchers $[19,20]$. It is interesting that this tendency was confirmed not only in cases where certification-recertification was achieved at the same level (gold certification-recertification projects), but also in cases where a higher certification level was achieved at recertification (silver certification-gold recertification projects).

In some of the analyzed recertification projects, the ability to achieve four bonus points increased the motivation of design teams to invest extra time, effort, and money into achieving the next certification level-in this case to go from silver (50 points) to gold (60 points). However, to get gold, scores in the WE/EA categories were mostly improved, whereas those in the MR/EQ categories worsened.

In addition, the platinum certification-recertification results are particularly noteworthy. Platinum (80 points) is the highest LEED certification level, which means that those who achieve it are highly motivated to build in an environmentally conscious way. Thus, it was surprising that scores in the MR and EQ categories worsened at recertification when a bonus was applied.

In three cases-gold certification-recertification, silver certification-gold recertification, and platinum certification-recertification with a bonus-sustainable purchasing credits such as MRc1-MRc5 were mainly responsible for the decreased MR category scores. These credits necessitate the purchase of a certain percentage of renewable, postconsumer, and/or postindustrial materials instead of natural materials to achieve credits related to ongoing consumables, electric-powered equipment, furniture, facility alterations, and additions. However, as was discussed in previous empirical studies involving LEED certification, it may be difficult to reduce the use of natural materials [19].

In both gold certification-recertification and platinum certification-recertification projects involving a bonus, scores for Indoor Air Quality Best Management Practices credits, such as EQc1.1-EQc1.5 were the main contributors to the lowering of EQ category scores. These credits concern decreasing the concentration of hazardous particulate contaminants inside buildings using natural and mechanical means of air ventilation. These issues are highly important for human well-being, especially in office buildings like those analyzed in this study [8].

Thus, overall, at the category level, the recertification results confirm previously reported LEED-certified empirical results showing greater scores in the SS, WE, and EA categories than in the MR and EQ categories. For example, empirical studies related to LEED-NC 2009-certified projects in both the USA and globally [19] and in 10 USA states [20] found low MR and medium EQ achievements. At the same time, in LEED-NC v2.2 projects analyzed all over the world, scores in the EA category were shown to greatly improve in projects moving from certified to silver, silver to gold, and gold to platinum [18]. In LEED-CI 2009 projects analyzed in 14 USA states, scores in both the EA and WE categories greatly improved when moving from silver to gold [21].

\section{Conclusions}

This study analyzed the influence of a four-point bonus system on recertification strategies for three cases-gold certification-recertification, silver certification-gold recertification, and platinum certification-recertification-in four metropolitan cities of the USA: Washington DC, Chicago, New York City, and San Francisco. It was revealed that, at recertification, (i) in the projects that received a four-point bonus, the scores achieved in the MR/EQ categories decreased, and (ii) in projects that did not receive a four-point bonus, the scores achieved in the MR/EQ categories increased. This was correct for the projects that retained their certification level (gold) at certification-recertification as well as those that moved from silver at certification to gold at recertification. The tendency for 
a decrease in MR/EQ scores in cases that received bonus points also held for platinum certification-recertification projects. Low MR achievements were associated with purchasing credits that require to replace natural materials with renewable and reused materials and low EQ achievements were associated with indoor air quality practice credits which aim to reduce particle contamination inside buildings.

It may be difficult to compare the effect of the four-point bonus offered by LEED-EB 2009 to the 10-point bonus suggested by LEED-EB v4.1. Theoretically, a 10-point bonus should be more effective than a four-point bonus. This is because that it can move certified (40 points) and silver (50 points) projects to the next higher certification level automatically, e.g., silver (50 points) and gold (60 points). This could become a reality if all categories (performance-based and other credits in LEED-EB v4.1) were kept at the same achievement level at recertification as was present at the time of initial certification.

However, the results from LEED-EB 2009 certification-recertification projects suggest that, in practice, this may not be the case for LEED-EB v4.1 projects. Thus, the current structure of LEED, which allows flexibility by allowing different credits to replace others and employing new credits during recertification, may serve to impede the intended effect of the 10-point bonus applied in LEED-EB v4.1 to increase the building recertification level. The empirical evidence gained on LEED-EB 2009 certification-recertification strategies could help LEED stakeholders to improve the bonus system in order to increase the environmental effectiveness of LEED buildings.

The effect of the bonus system may be more noticeable in LEED-EB v4.1 projects than in LEED-EB 2009 projects. To confirm/refute this point of view, it is necessary to study the certification-recertification procedure for LEED-EB v4.1 projects.

Funding: This research received no external funding.

Institutional Review Board Statement: Not applicable.

Informed Consent Statement: Not applicable.

Data Availability Statement: Data supporting reported results can be found at the USGBC Project Site. Available online: https://www.usgbc.org/projects, (accessed on 10 June 2021) and GBIGThe Green Building Information Gateway. Available online: http:/ /www.gbig.org, accessed on 10 June 2021.

Conflicts of Interest: The author declares no conflict of interest.

\section{References}

1. WBCSD 2018. SBT4 Buildings: A Framework for Carbon Emissions Management along the Building and Construction Value Chain, World Business Council for Sustainable Development. 2018. Available online: https://www.wbcsd.org/Programs/Citiesand-Mobility/Sustainable-Cities/Science-based-targets / Resources/framework-carbon-emissions-management-buildingconstruction-value-chain (accessed on 13 August 2021).

2. Sartori, T.; Drogemuller, R.; Omrani, S.; Lamari, F. A schematic framework for Life Cycle Assessment (LCA) and Green Building Rating System (GBRS). J. Build. Eng. 2021, 38, 102180. [CrossRef]

3. Lu, D.; Realff, M.J. The design of a sustainability assessment standard using life cycle information. J. Ind. Ecol. 2012, 17, 493-503. [CrossRef]

4. Vierra, S. Green Building Standards and Certification Systems vol. 27, Green Building Standards and Certification Systems. 2014. Available online: https:/ / www.wbdg.org/resources/green-building-standards-and-certification-systems (accessed on 3 June 2021).

5. Leung, B.C.-M. Greening existing buildings [GEB] strategies. Energy Rep. 2018, 4, 159-206. [CrossRef]

6. Matisoff, D.C.; Noonan, D.S.; Flowers, M.E. Policy monitor-Green buildings: Economics and policies. Rev. Environ. Econ. Policy. 2016, 10, 329-346. [CrossRef]

7. Eisenstein, W.; Fuertes, G.; Kaam, S.; Seigel, K.; Arens, E.; Mozingo, L. Climate co-benefits of green building standards: Water, waste and transportation. Build. Res. Inform. 2017, 45, 828-844. [CrossRef]

8. Phillips, H.; Handy, R.; Sleeth, D.; Matthew, S.; Schaefer, C.; Stubbs, J. Taking the “LEED” in Indoor Air Quality: Does Certification Result in Healthier Buildings? J. Green Build. 2020, 15, 55-66. [CrossRef]

9. Scofield, J.H.; Brodnitz, S.; Cornell, J.; Liang, T.; Scofield, T. Energy and Greenhouse Gas Savings for LEED-Certified U.S. Office Buildings. Energies 2021, 14, 749. [CrossRef] 
10. Adekanye, O.G.; Davis, A.; Azevedo, I.L. Federal policy, local policy, and green building certifications in the U.S. Energy Build. 2020, 209, 109700. [CrossRef]

11. Wu, Z.; Lib, H.; Feng, Y.; Luo, X.; Chen, Q. Developing a green building evaluation standard for interior decoration: A case study of China. Build Environ. 2019, 152, 50-58. [CrossRef]

12. Choi, E. Green on buildings: The effects of municipal policy on green building designations in America's central cities. J. Sustain. Real Estate 2010, 2, 1-21. [CrossRef]

13. Kok, N.; McGraw, M.; Quigley, J.M. The diffusion of energy efficiency in building. Am. Econ. Rev. 2011, 101, 77-82. [CrossRef]

14. Simcoe, T.; Toffel, M.W. Government green procurement spillovers: Evidence from municipal building policies in California. J. Environ. Econ. Manag. 2014, 68, 411-434. [CrossRef]

15. Fuerst, F.; Kontokosta, C.; McAllister, P. Determinants of green building adoption. Environ. Plan. B-Plan. Des. 2014, 41, 551-570. [CrossRef]

16. York, J.G.; Vedula, S.; Lenox, M.J. It's not easy building green: The impact of public policy, private actors, and regional logics on voluntary standards adoption. Acad. Manag. J. 2018, 61, 1492-1523. [CrossRef]

17. Fuerst, F. Building momentum: An analysis of investment trends in LEED and Energy Star-certified properties. J. Retail Leis. Prop. 2009, 8, 285-297. [CrossRef]

18. Wu, P.; Mao, C.; Wang, J.; Song, Y.Z.; Wang, X.Y. A decade review of the credits obtained by LEED v2.2 certified green building projects. Build. Environ. 2016, 102, 167-178. [CrossRef]

19. Wu, P.; Song, Y.Z.; Shou, W.C.; Chi, H.L.; Chong, H.Y.; Sutrisna, M. A comprehensive analysis of the credits obtained by LEED 2009 certified green buildings. Renew. Sustain. Energy Rev. 2017, 68 Pt 1, 370-379. [CrossRef]

20. Pushkar, S.; Verbitsky, O. LEED-NCv3 Silver and Gold certified projects in the US: An observational study. J. Green Build. 2018, 13, 67-83. [CrossRef]

21. Pushkar, S.; Verbitsky, O. Silver and gold LEED commercial interiors: Certified projects. J. Green Build. 2019, 14, 95-113. [CrossRef]

22. Flowers, M.E.; Matisoff, D.C.; Noonan, D.S. In the LEED: Racing to the top in environmental self-regulation. Bus Strat. Environ. 2020, 29, 2842-2856. [CrossRef]

23. LEED-EB 2009. LEED 2009 for Existing Buildings: Operations \& Maintenance. Available online: https://energy.nv.gov/ uploadedFiles/energynvgov/content/Progras/2009_EBOM.pdf (accessed on 21 August 2021).

24. LEED-EBv4 2018 LEED v4 for Building Operations and Maintenance. Available online: http:/ /greenguard.org/uploads/images/ LEEDv4forBuildingOperationsandMaintenanceBallotVersion.pdf (accessed on 10 February 2020).

25. Trovato, M.R.; Francesco Nocera, F.; Giuffrida, S. Life-Cycle Assessment and Monetary Measurements for the Carbon Footprint Reduction of Public Buildings. Sustainability 2020, 12, 3460. [CrossRef]

26. USGBC. Projects Site. Available online: https://www.usgbc.org/projects (accessed on 21 August 2021).

27. GBIG. The Green Building Information Gateway. Available online: http://www.gbig.org (accessed on 21 August 2021).

28. Meehl, P.E. Appraising and amending theories: The strategy of Lakatosian defense and two principles that warrant it. Psychol. Inq. 1990, 1, 108-141. [CrossRef]

29. Pushkar, S. Sacrificial Pseudoreplication in LEED Cross-Certification Strategy Assessment: Sampling Structures. Sustainability 2018, 10, 1353. [CrossRef]

30. Chi, B.; Lu, W.; Ye, M.; Bao, Z.; Zhang, X. Construction waste minimization in green building: A comparative analysis of LEED-NC 2009 certified projects in the US and China. J. Clean. Prod. 2020, 256, 120749. [CrossRef]

31. Mundry, R.; Fischer, J. Use of statistical programs for nonparametric tests of small samples often leads to incorrect $P$ values: Examples from animal behaviour. Anim. Behav. 1998, 56, 256-259. [CrossRef] [PubMed]

32. Pham, D.H.; Kim, B.; Lee, J.; Ahn, Y. An Investigation of the Selection of LEED Version 4 Credits for Sustainable Building Projects. Appl. Sci. 2020, 10, 7081. [CrossRef] 